\title{
The Influence of Service Recovery Strategy and Regulatory Focus on Satisfaction in Online Shopping
}

\author{
Liang Chenglei ${ }^{1}$ \\ Dongfang College, ShanDong University of Finance \\ and Economics \\ Taian, China \\ liangchenglei@163.com
}

\author{
Li Xiurong ${ }^{2}$ \\ ShanDong University of Finance and Economics \\ Jinan, China \\ xiurong588@163.com
}

\begin{abstract}
In this paper, chooses service failure and recovery of online shopping as the study's objective, analyses the effect of two different regulatory focus (promotion focus and prevention focus) and service recovery strategy on satisfaction. The results find that: the regulatory fit which arises from regulatory focus and service recovery strategy has significantly influence on perception fairness; perception fairness has significantly influence on satisfaction.
\end{abstract}

Keywords-regulatory focus; service recovery strategy; satisfaction; perception fairness

\section{INTRODUCTION}

With the increasingly fierce competition of online sales, how to retain customers have become a key issue in the development of enterprises(Bo-Shiun $\mathrm{Wu}, 2011)^{[1]}$.

Some studies have shown that, retaining old customers have more beneficial than developing new customers, because the customer retention rate is higher, enterprises have more and more profits.

Some studies also have shown that, the service failure often leads to the loss of customers, especially the service failure has not been properly solved.

The service failure will lead to lower customer satisfaction, dissatisfied customers may choose other enterprises.

The service failure is inevitable, when the service failure occurs, the customer will hope to get the corresponding compensation. So service recovery has become the key to the enterprise to keep a consumer.

When the service failure occurs, taking appropriate service recovery strategy to achieve the best remedial effect, and enhancing client continual intention has become a focus of research.

Previous research on service recovery focused on the hypostatic shopping, but there are many differences between online shopping and hypostatic shopping, whether previous research results can be applied to the online shopping, it still needs further study.

In essence, the evaluation and adoption of service recovery strategy for online shopper are a process of goal achievement, relying on self regulating system, which an individual pursues their goals.

This paper use the concept of regulatory focus to measure different individual.
Based on previous research, this paper chooses the concept of service recovery strategy as independent variables, combined with regulatory focus which is one of personality factors, analyses the effect of those independent variables on satisfaction.

\section{LITERATURE REVIEW}

\section{A. Service Recovery}

Fornell \& Wernerfelt (1988) found that, in the process of resolving the customer complaint, if customer complaints are resolved, $54 \%$ of the customers will stay; If the complaint is not resolved, only $9 \%$ of the clients will stay. This finding shows that there is a close relationship between the consumer's future purchase intention and service recovery ${ }^{[2]}$.

Varela-Neira (2008) presents a seemingly illogical situation, consumers experienced service failures, then the service failure was solved, consumers will have a higher satisfaction than those who did not experience service failures $^{[3]}$.

Orsingher(2010)found that, in the perception fairness, distributive justice and complaint satisfaction have the closest correlation, followed by interactive justice, the procedural justice. The results highlight that substantial recovery has a central role in service recovery.

Oliver(1989) 、Swan 、 Smith(1999)、Liao(2007) 、 Schoefer(2008)、Santos \& Fernandes(2008)all made a similar point of view.

Service recovery can be divided into three types: substantial recovery, efficient recovery, psychological recovery.

Substantial recovery can be divided into two types: cash recovery and discount recovery.

\section{B. Perception Fairness}

Smith et al. (1999) believes that the perceived fairness has been positioned as a concept which has three dimensions: perception distributive justice, perception procedural justice, perception interactional justice ${ }^{[4]}$.

Santos \& Fernandes (2008)believes that distributive justice is seen as tangible results provided for complainer (such as product replacement or refund), procedural justice relates to policies and procedures used by the company, interactive justice relates to the way of handling complaints and way of communicating with consumers by staffs ${ }^{[5]}$. 
Orsingher (2010) finds that, distributive justice and satisfaction have the closest correlation, followed by interactive justice, the procedural justice. The results highlight that substantial recovery has a central role in service recovery ${ }^{[6]}$.

In previous studies, scholars often focus on consumer emotional response and an overall evaluation of the service recovery.

Only a few scholars study on the effect of personality on perceived fairness.

\section{Regulatory Focus Theory}

Regulatory focus meant that as the motivation intensity increased that results when there is a match between the way in which a person achieves a goal and one' goal orientation (Avnet \& Higgins, 2006) ${ }^{[7]}$.

There are two different types of regulatory focus: promotion focus and prevention focus. In the process of achieving goals, a person who is more promotion focused the achievement of positive results, individuals experience the emotion of joy-depression.

A person who is more promotion focused the avoid of negative results, individuals experience the emotion of relaxanger.

People will experience fit in the process of achieving goals when they adopt pursuit strategy in activities that match their goal orientation (Avnet \& Higgins, 2006) ${ }^{[7]}$.

When this happens, it will produce a value based on the process, different from the traditional value based on the resulting, and will enhance the individual behavior motivation, will produce high performance, can has moderating effect between behavior and psychology, will affect other activities or behavior follow- up.

\section{THE RESEARCH HYPOTHESIS}

When the service failure happens, network enterprise needs to solve customer's problems by providing compensation to the client.

What kind of recovery strategies provided by the enterprise consumers tend to adopt will be the core problem in the field of service recovery.

In order to resolve the issues, we need to consider the difference between individuals. Regulatory focus is a general principle of motivation, has an influence on the basic psychological process of people, such as cognitive evaluation, decision and behavior strategy.

In the process of achieving goals, a person who is more promotion focused on the achievement of positive results; a person who is more promotion focused on the avoidance of negative consequences.

When regulatory fit happens, it will produce a value based on the process, an individual will experience a correct sense, that the experience will enhance the individual behavior motivation, and will produce high performance.

Therefore when an individual who is more promotion focused adopt the discount recovery strategy will experience the fit, he will generate a feeling that he will get the realization of positive goals and desired end states, then he will prefer this recovery strategies.
When an individual who is more prevention focused adopt the cash recovery strategy will experience the fit, he will generate a feeling that he will preserve an absence negative positive goals, then he will prefer this recovery strategy.

Smith \& Bolton (1998), Kau \& Loh (2006) finds that perception fairness has significantly influence on satisfaction in their study ${ }^{[8,9]}$. The direct effect of service recovery is the increase of customer perceived fairness, and they will increase their satisfaction, increase their loyalty and repurchase behavior.

So some hypotheses will put forward as follows:

H1: the regulatory fit which arises from regulatory focus and service recovery strategy has significantly influenced on perceived fairness.

Individual who is more promotion focused will prefer this discount recovery strategy.

Individual who is more prevention focused will prefer cash recovery strategy.

H2: perception fairness has significantly influence on satisfaction.

\section{RESEARCH MethodS}

\section{A. Experimental Design}

In this paper, choose consumers who had service failure experience in online shopping as the object of study, a total of 172 people (male 90, female 82, average age was 21.3 years).

All respondents were measured with the questionnaire of regulatory focus in China, select respondent with the method of factor analysis, finally get the sample size for 116 .

This research chooses regulatory focus (promotion or prevention) and service recovery strategies (cash or discount) as independent variables, the dependent variable is the satisfaction.

In this paper, choose the pricing errors as the service failure context. Context includes two types.

The context is as follows: if you shop online, you find windbreaker original price 680yuan each, now special 290 yuan each, you place an order to buy at once being jubilant. On the second day, enterprises issues a notice on the Internet. Yesterday the price of a windbreaker is wrong.

Recovery strategy of enterprises is proposed that consumers who had purchased can buy the goods with the price of 400 yuan in context A.

Recovery strategy of enterprises is proposed that consumers who had purchased can buy the goods at a $40 \%$ discount in context B.

\section{B. Variables Definition}

In this paper, choose the questionnaire of regulatory focus in China to measure respondent's regulatory focus. Based on Tax \& Smiths studies, designed a questionnaire to measure perceived fairness and satisfaction.

The questionnaires have high validity and reliability. 


\section{RESUlt AND ANALYSIS}

A. Impacts of the Service Recovery Strategy and Regulatory Focus on Perception Fairness

To discuss whether different service recovery strategy will differently influence the perception fairness with diverse service recovery strategy, choose ANOVA to test the hypothesis.

The results are as following: the regulatory fit which arises from regulatory focus and service recovery strategy has significantly influence on perception fairness $(F=18.343$, $\mathrm{P}=0.000)$.

In the context of discount recovery strategies, an individual who is more promotion focused will prefer this discount recovery strategies.

Individual who is more prevention focused will prefer cash recovery strategy.

Hypothesis one is verified.

\section{B. Impacts of the Perception Fairness on Satisfaction}

Perceived fairness is positively related to satisfaction, the results by using regression analysis method are as following: Satisfaction's standardized coefficients is 0.826 .

This illustrates perception fairness has significantly influence on satisfaction.

Consumers' perceived fairness is higher, the stronger the satisfaction; Consumers' perception fairness is lower, the lower satisfaction.

Hypothesis two is verified.

The result of the impacts of $t$ perception fairness on satisfaction is shown in Table I.

TABLE I. IMPACTS OF T PERCEPTION FAIRNESS ON SATISFACTION

\begin{tabular}{|c|c|c|c|c|c|}
\hline \multirow{2}{*}{ Model } & \multicolumn{2}{|c|}{$\begin{array}{l}\text { Unstandardized } \\
\text { Coefficients }\end{array}$} & \multirow{2}{*}{$\begin{array}{c}\begin{array}{c}\text { Standardiz } \\
\text { ed } \\
\text { Coefficient } \\
s\end{array} \\
\text { Beta }\end{array}$} & \multirow{2}{*}{$t$} & \multirow{2}{*}{ Sig. } \\
\hline & B & $\begin{array}{l}\text { Std. } \\
\text { Error }\end{array}$ & & & \\
\hline (Constant) & -1.676 & 0.602 & \multirow{2}{*}{0.826} & -2.078 & 0.012 \\
\hline satisfaction & 1.102 & 0.112 & & 7.782 & 0.000 \\
\hline
\end{tabular}

\section{DISCUSSION AND CONCLUSION}

\section{A. Conclusion}

From the above results, we can get the following conclusion: When service recovery strategy match with regulatory focus, the level of perceived fairness was higher; perceived fairness is positively related to satisfaction.

Individual who is more promotion focused will prefer this discount recovery strategy.
Individual who is more prevention focused will prefer cash recovery strategies. This is because that, after the match occurs, consumers have a correct sense arising from matching.

When people face the decision, people often ask themselves "how I feel ". Current feelings will affect the decision at hand.

If people's answer is "correct sense", this feeling will eventually become a convincing, will make people more willing to accept the proposal.

Customers feel more sense of fair, the more higher the satisfaction after service recovery.

A satisfied customer is likely to become loyal customers, and bring more profit to the enterprise ${ }^{[10]}$.

\section{B. Management Implications}

Service failure is inevitable, in addition to reducing faults that should not occur, we should take different service recovery strategy based on the customer's difference.

Companies can provide highly individualized service recovery strategy according to the customer's different orientation, therefore, enterprises can establish and design a marketing database, classifies consumer's characteristics and goal orientation, and improve the enterprise's marketing efficiency.

\section{REFERENCES}

[1] Bo-Shiun Wu, "Applying Expectation Model and Justice Theory for Online Service Failure Recovery”, D. Master thesis, Providence University, Taiwan, (2011)1-4 (In Chinese)

[2] Fornell \& Wernerfelt, “A Model for Customer Complaint Management”, J. Marketing Science,7(1988), p. 287-298.

[3] Varala-Neira \& Iglesias-Arguelles, "The Influence of Emotions on Customers' Cognitive Evaluations and Satisfaction in a Service Failure and Recovery Context”, J. The Service Industries Journal, 28(2008), p. 497-512.

[4] Smith et al., "A Model of Customer Satisfaction With Services Encounter Involving Failure and Recovery”, J. Journal of Marketing Research, 36(1999), p. 356-372.

[5] Santos \& Fernandes, "Antecedents and Consequences of Consumer Trust in the Context of Service Recovery”, J. Brazilian Administration Review, 5(2008), p. 225-244.

[6] Orsingher et al., "A Meta-Analysis of Satisfaction With Complaint Handling in Services”, J. Journal of the Academic Marketing Science, 38(2010), p. 169-186.

[7] Avnet \& Higgins, "How regulatory fit Affect Value in Consumer Choice and Opinions”, J. Journal of Marketing Research, 43(2006), p. 1-10.

[8] Smith \& Bolton, “An Experimental Investigation of Customer Reactions to Service Failure and Recovery Encounters:Paradox or Peril?”, J. Journal of Service Research, 1(1998), p. 65-81.

[9] Kau \& Loh, "The Effects of Service Recovery on Consumer Satisfaction:A Comparison Between Complainants and Noncomplainants”, J. Journal of Services Marketing, 20(2006), p. 101111.

[10] Higgins, E. T. et al., “Transfer of Value From Fit”, J. Journal of Personality and Social Psychology, 84(2003), p. 1140-1153. 